\title{
Knowledge and Practices of Student Nurses of NRI College of Nursing in Application of SSKIN towards Prevention of Pressure Ulcers in NRI Hospital, Chinakakani, Mangalagiri, Guntur (Dt). AP
}

\section{Bollineni NJ* \\ Department of Community Health Nursing, NRI College of Nursing, India}

*Corresponding author: Nirmala Jyothi Bollineni, Department of Community Health Nursing, NRI College of Nursing, India, Email: bnjyothi30@gmail.com

\section{Review Article \\ Volume 2 Issue 4}

Received Date: June 29, 2018

Published Date: July 26, 2018

\section{Abstract}

Background: Pressure ulcers are the common conditions among patients hospitalized in acute and chronic care facilities and impose significant burden on patients, their relatives and caregivers. Pressure ulcer lead to pain and discomfort for patients and also cause prolong illness, delay restoration, increase patient's hospital stay, and may lead to infirmity and even death. The purpose of this study was to assess the student nurse's knowledge and practices towards pressure ulcer prevention.

Materials and Methods: A descriptive study among 84 student nurses was conducted in NRI College of Nursing. The study participants were selected by convenient sampling technique. A questionnaire on SSKIN (Surface, Skin inspection, Keep moving, Incontinence and Nutrition) aspects distributed among study participants. Data entered in master analysis sheet and analyzed for descriptive statistics and results presented in Graphs and Tables.

Results: The Student Nurses overall mean knowledge score was (20.8 \pm 3.72$)$ and $51.1 \%$ of respondents scored above mean who have been considered in the category of good knowledge about pressure ulcer prevention. The overall mean score for practices of respondents was $(27.8 \pm 5.38)$ and about $51.1 \%$ of them had secured above mean score and considered having adequate practices and remaining has inadequate practices of pressure ulcer prevention. There was a significant correlation $\left(\mathrm{r}=0.36 \mathrm{df}=83<0.05^{* *}\right)$ with their practices and knowledge toward pressure ulcer prevention.

Conclusion: The student nurses overall knowledge and practices toward pressure ulcer are poor and inadequate. Hence the student nurses who are going to become full pledged nurses within few months need to get continuing education and training about pressure ulcer prevention that will enhance their knowledge and practices can be improved.

Keywords: Knowledge; Practices; Student Nurses; Pressure ulcer; Prevention; SSKIN (Surface; Skin inspection; Keep moving; Incontinence and Nutrition) 


\section{Nursing \& Healthcare International Journal}

\section{Introduction}

A pressure ulcer is localized injury to the skin and/or underlying tissue usually over a bony prominence, as a result of pressure, or pressure in combination with shear. A number of contributing or confounding factors are also associated with pressure ulcers; the significance of these factors is yet to be elucidated [1-3]. Pressure ulcers are the common conditions among patients hospitalized in acute and chronic care facilities and impose significant burden on patients, their relatives and caregivers [1,2]. Now days, pressure ulcers are recognized worldwide as one of the five most common causes of harm to patients and preventable patient safety problem. It is also increasingly described as an indicator of the quality of care provided by health care organizations $[1,2]$.

Pressure ulcers have been described as one of the most costly and physically debilitating complications since the $20^{\text {th }}$ century [1]. The pain and discomfort due to pressure ulcer prolongs illness, rehabilitation, time of discharge and even contribute to disability and death. World stop pressure ulcer day report in 2014 showed that nearly 7, 00,000 patients were affected by pressure ulcers each year. Around 1, 86,617 patients develop a new pressure ulcer in acute care each year. This has shown that in the year January 2012 to December 2013 between 4 and $6 \%$ of patients in acute care settings and more than $5-10 \%$ of patients in non acute care had pressure ulcers. Pressure ulcers are accountable for $2 \%$ of preventable deaths [4-7].

According to an international literature, it has been identified that nurses' knowledge of the prevention of pressure ulcers is poor, which is reflected in their practices as they do not comply with best practice guidelines [6]. There is a gap between nurse's knowledge of pressure ulcer prevention and the utilization of this knowledge according to proper standards in their practices. Nurses have good knowledge regarding pressure ulcers but they have poor practices regarding pressure ulcers prevention [7]. In India there is very negligible data available in this area of research. Hence this present study was aimed to assess knowledge and practices towards prevention of pressure ulcers among student nurses of NRI College of nursing who are going to be the full pledged nurses within few months.

\section{Objectives of the Study}

1. To assess the knowledge of student nurses towards prevention of pressure ulcers.
2. To assess the practices of student nurses towards prevention of pressure ulcers.

3. To find out the correlation between knowledge and practices of student nurses towards prevention of pressure ulcers.

\section{Operational Definitions}

Pressure ulcer: It refers to a lesion of skin or underlying tissues by direct unrelieved pressure for more than 3 hours on the skin.

Knowledge: It refers to the student Nurses who scored above the mean score of the knowledge questions, were considered as having good knowledge on pressure ulcer prevention. But in the contrarily, those scored below the mean value considered as having poor knowledge towards prevention of pressure ulcer.

Practices: It refers to the students Nurses who scored above the mean score of the practice questions related to prevention of pressure ulcer were considered to have good practice. But in the contrarily, those who scored below the mean score were considered as having poor practice towards prevention of pressure ulcer.

SSKIN: It refers to the nomenclature which denotes: Surface, Skin inspection, Keep moving, Incontinence and Nutrition/Rehydration and from which the knowledge and practice items were prepared to test the subjects.

\section{Methods and Materials}

An institutional based quantitative and descriptive study design was conducted among student nurses who are studying in NRI College of nursing and posted for their clinical practice in NRI hospital. The hospital is located in Chinakakani Guntur (Dt) of AP. The hospital was established in 2003 and provides outpatient and inpatient services to peoples living in its catchment area. The study subjects in the present study were all, B.Sc. N $4^{\text {th }}$ years, P B B.Sc. $\mathrm{N} 1^{\text {st }}$ and $2^{\text {nd }}$ years and M.Sc. $\mathrm{N} 1^{\text {st }}$ and $2^{\text {nd }}$ year students studying in NRI College of nursing. A sample size of 100 was taken by using convenient sampling technique. The study involved all of them to increase the power of the study.

\section{Data Collection Tool and Procedure}

The data were collected using a structured and adopted [2-4] pretested self administered questionnaire on SSKIN (Surface, Skin inspection, Keep moving, Incontinence and Nutrition) aspects. The questionnaire 
and the consent form were prepared in English. Participants were asked 30 knowledge based and 20 practice based questions to assess their level of knowledge and practices towards prevention of pressure ulcer. Appropriate modifications were made after analyzing the pre-tested result before the actual data collection. The knowledge items had two options correct and incorrect and the correct option was given a score of ' 1 ' and incorrect option was given a score of ' 0 ' with a total score of 30 . There were 20 practice items on prevention of pressure ulcers. A score of ' 2 ' was given for always, ' 1 ' for some times and ' 0 ' for never and the total score for practices was 40 .

Data Processing and Analysis: The data were entered in to excel master analysis sheet and then the data were cleaned and analyzed by using descriptive statistics.
Significance of statistical association was assured or tested using 95\% confidence interval (CI) and $p$ value $(<0.05)$.

\section{Results of the Study}

\section{Socio-Demographic Characteristics of the Study}

Participants out of the expected 100 respondents, 84 participated in the study. Majority $90.5 \%$ of the respondents were in the age group of 20-25 years. Most $76.2 \%$ of respondents were female. About $61.9 \%$ were B.Sc. N $4^{\text {th }}$ year's students and the remaining of them were post graduates. Majority of the respondents had expressed that they had received training on prevention of pressure ulcers during their training period (Table 1).

\begin{tabular}{|c|c|c|c|}
\hline \multirow{3}{*}{ Sl. No } & Demographic characteristics & (f) & (\%) \\
\hline \multirow{4}{*}{1} & Age in years & & 90.5 \\
\cline { 2 - 4 } & a) 20 - 25 years & 76 & 9.5 \\
\hline \multirow{4}{*}{2} & b) 26- 30 years & 8 & 23.8 \\
\cline { 2 - 4 } & Gender & 20 & 76.2 \\
\hline \multirow{4}{*}{3} & a) Male & 46 & 61.9 \\
\cline { 2 - 4 } & b) Female & 52 & 5.9 \\
\cline { 2 - 4 } & Level of Education & 5 & 32.2 \\
\hline \multirow{4}{*}{4} & a) B.Sc. Nursing 4th year & 27 & 11.9 \\
\cline { 2 - 4 } & b) Post Basic B.Sc. Nursing & 10 & 77.4 \\
\cline { 2 - 4 } & c) M.Sc. Nursing & 65 & 10.7 \\
\cline { 2 - 4 } & Do you read review of literature on prevention of pressure ulcers? & 9 & \\
\hline \multirow{3}{*}{5} & a) Always & 60 & 71.4 \\
\cline { 2 - 4 } & b) Sometimes & 4 & 4.7 \\
\cline { 2 - 4 } & c) Never & 16 & 19 \\
\cline { 2 - 4 } & How did you receive training about management and prevention of pressure ulcer & 4.7 \\
\cline { 2 - 4 } & among hospitalized patients & 4 & \\
\cline { 2 - 4 } & a) During course & & \\
\hline
\end{tabular}

Table 1: Distribution of the samples based on their demographic characteristics.

\section{Knowledge of Pressure Ulcer Prevention}

Participants were asked 30 questions to assess their knowledge on pressure ulcer prevention, and they were categorized in to two groups based on their score in relation to the mean. The mean score was $20.8( \pm 3.72)$ (Table 2). Just more than half (51.1\%) of the respondents were found to have good knowledge, while a substantial proportion $(48.9 \%)$ of the respondents were not (Table 3 ). From the six dimensions of knowledge regarding prevention of pressure ulcer, the nurses had a poor knowledge on three including risk assessment, skin care and management for mechanical loads. But, they possessed a good knowledge on risk factors related to 


\section{Nursing \& Healthcare International Journal}

pressure ulcer formation such as prolonged immobility $91.7 \%$, and constant pressure $84.5 \%$ where as only $39.3 \%$ of the respondents felt that malnutrition can lead to pressure ulcers (Tables $3 \& 4$ ).

\begin{tabular}{|c|c|c|c|}
\hline Variable & Mean & SD & $\begin{array}{c}\text { 'r' value } \\
\text { 'p' value }\end{array}$ \\
\hline Knowledge & 20.8 & 3.72 & $\mathrm{r}=0.36$ \\
\cline { 4 - 4 } & & $\mathrm{df}=83$ \\
\hline Practices & 27.8 & 5.38 & $<0.05^{* *}$ \\
\hline
\end{tabular}

Table 2: Correlation between knowledge and practices scores of student nurses towards prevention of pressure ulcers. $n=84$

\begin{tabular}{|c|c|c|}
\hline Variables & (f) & (\%) \\
\hline Level of Knowledge & & \\
\hline Good knowledge (above mean 20.8) & 43 & 51.1 \\
\hline Poor Knowledge (below mean 20.8) & 41 & 48.9 \\
\hline & & \\
\hline Level of Practices & & \\
\hline Adequate practices (above mean 27.8) & 43 & 51.1 \\
\hline Inadequate practices (below mean 27.8) & 41 & 48.9 \\
\hline
\end{tabular}

Table 3: Comparison of Distribution of students Nurses' level of overall knowledge and practices regarding prevention of pressure ulcer.

\begin{tabular}{|c|c|c|c|c|c|}
\hline \multirow{2}{*}{ Sl.no } & $\begin{array}{c}\text { Risk factors and patients at risk for } \\
\text { pressure ulcer }\end{array}$ & \multicolumn{2}{|c|}{ Right } & \multicolumn{2}{c|}{ Wrong } \\
\cline { 3 - 6 } & (f) & (\%) & (f) & (\%) \\
\hline 1.1 & Prolonged immobility & 77 & 91.7 & 7 & 8.3 \\
\hline 1.2 & Constant pressure/compression & 71 & 84.5 & 13 & 15.5 \\
\hline 1.3 & Friction/shear & 43 & 51.2 & 41 & 48.8 \\
\hline 1.4 & Moist surfaces in which patients lie & 61 & 72.6 & 23 & 27.4 \\
\hline 1.5 & Using improper support materials & 56 & 66.7 & 28 & 33.3 \\
\hline 1.6 & Diabetic mellitus & 55 & 65.5 & 29 & 34.5 \\
\hline 1.7 & Hypoxemia & 45 & 53.6 & 39 & 46.4 \\
\hline 1.8 & Malnutrition and Anemia & 33 & 39.3 & 51 & 60.7 \\
\hline 1.9 & Ischemic heart diseases & 25 & 29.8 & 59 & 70.2 \\
\hline 1.1 & Spinal cord injury & 58 & 69.9 & 26 & 30.1 \\
\hline
\end{tabular}

Table 4: Frequency and percentage distribution of subject's response on Risk factors and Patients at risk for pressure ulcer assessment.

\begin{tabular}{|c|c|c|c|c|c|}
\hline \multirow{2}{*}{ Sl.no } & Knowledge about pressure ulcer assessment and prevention & \multicolumn{2}{|c|}{ Right } & \multicolumn{2}{|c|}{ Wrong } \\
\cline { 4 - 5 } & (f) & (\%) & (f) & (\%) \\
\hline 1 & $\begin{array}{c}\text { High loading pressure is the contributing factor for pressure ulcer } \\
\text { formation }\end{array}$ & 68 & 80.1 & 16 & 19.9 \\
\hline 2 & $\begin{array}{c}\text { Immobility is the most important factor for pressure ulcer Formation } \\
\text { in an 80 years old man with fracture hip and Bedridden. }\end{array}$ & 78 & 92.9 & 6 & 7.1 \\
\hline 3 & $\begin{array}{c}\text { Faeces is the favourable environment for bacterial growth in the form } \\
\text { of maceration for a young man having head injury with } \\
\text { unconsciousness }\end{array}$ & 56 & 66.7 & 28 & 33.3 \\
\hline 4 & Low albumin is the critical determinant for pressure ulcer formation & 40 & 67.6 & 44 & 52.4 \\
\hline 5 & $\begin{array}{c}\text { Head to toe skin assessment is an assessment procedure for a patient } \\
\text { with spinal cord injury who is at high risk for pressure ulcer } \\
\text { development }\end{array}$ & 66 & 78.6 & 18 & 21.4 \\
\hline 6 & $\begin{array}{c}\text { Braden scale is the risk assessment scale for pressure ulcer } \\
\text { development }\end{array}$ & 65 & 77.4 & 19 & 22.6 \\
\hline 7 & $\begin{array}{c}\text { Risk assessment scale is an appropriate method for assessing an } \\
\text { individual who is at risk for pressure ulcer development }\end{array}$ & 52 & 61.9 & 32 & 38.1 \\
\hline
\end{tabular}




\section{Nursing \& Healthcare International Journal}

\begin{tabular}{|c|c|c|c|c|c|}
\hline 8 & $\begin{array}{c}\text { Partial skin loss with blister and abrasion is correct answer for the } \\
\text { sign of stage II pressure ulcer }\end{array}$ & 56 & 66.7 & 28 & 33.3 \\
\hline 9 & Pale , red , or blue - gray discoloration on the skin is the sign for \\
pressure ulcer development & 68 & 80.1 & 16 & 19.9 \\
\hline 10 & Topical cream is appropriate method for skin care & 60 & 71.4 & 24 & 28.6 \\
\hline 11 & Turn position for every 2 hours is significant activity for protecting \\
skin damage & 69 & 82.1 & 15 & 17.9 \\
\hline 12 & $\begin{array}{c}\text { Cleansing soil and using skin barrier cream or lotion activity is } \\
\text { appropriate for preventing maceration for a 78 - years old man having } \\
\text { a stroke with hemiplegic }\end{array}$ & 57 & 67.9 & 27 & 32.1 \\
\hline 13 & Lift up the patient without dragging is a correct practice for \\
maintaining skin integrity & 57 & 69.7 & 27 & 32.1 \\
\hline 14 & Vitamin C and E is important to maintain healthy skin & 76 & 90.5 & 8 & 9.5 \\
\hline 15 & Use pillow under the patients leg to prevent heel ulcer & 75 & 89.3 & 9 & 10.7 \\
\hline 16 & protein and high calorie needs to be offered to a 85- years Old \\
bedridden patient who has BMI < 18.5 & 59 & 70.2 & 25 & 29.8 \\
\hline 17 & $\begin{array}{c}\text { Serum albumin is an appropriate lab test for nutritional assessment of } \\
\text { pressure ulcer patient }\end{array}$ & 44 & 52.4 & 40 & 47.6 \\
\hline 18 & $\begin{array}{c}\text { Lift patient without dragging is appropriate activity to reduce friction } \\
\text { for an 80- year's old man having fracture hip with skeletal traction }\end{array}$ & 65 & 77.4 & 19 & 22.6 \\
\hline 19 & Elevate the head of bed < 30 is the activity for reducing shearing force & 45 & 53.6 & 39 & 46.4 \\
\hline 20 & $\begin{array}{l}\text { In- service training on pressure ulcer prevention is the best } \\
\text { Educational activity that enhances competency of staff nurses in } \\
\text { preventing pressure ulcer }\end{array}$ & 74 & 88.1 & 10 & 11.9 \\
\hline
\end{tabular}

Table 5: Frequency and percentage distribution of the student nurses' knowledge on prevention of pressure ulcer.

\section{Nurses' Practice Regarding to Prevention of Pressure Ulcer}

By using 20 practice based items the practice levels were assessed with a maximum score of 40 , the mean practice score of the respondents was found to be 27.8 ( \pm 5.38$)$ (Table 2$)$. Nearly half (51.1\%) of the respondents had good practices; whereas the remaining $48.9 \%$ respondents had poor practices of pressure ulcer prevention (Table 3). The significant correlation was found between knowledge and practices( $\mathrm{r}=0.36 . p$ value $<$ $0.05^{* *}$ at $95 \%$ confidence interval).

\section{Discussion}

Prevention of pressure ulcers is an indicator of quality of care. Nursing care has a major effect on pressure ulcer development and prevention. Hence, Pressure ulcers are a major nurse-sensitive outcome. So the present study was aimed to describe the level of nurse's knowledge and practice on prevention of pressure ulcers among students of NRI College of nursing. In this study, $51.1 \%$ of the participants were found to be having good knowledge with adequate practices respectively. While considerable size $48.9 \%$ were not having good and inadequate practices respectively towards prevention of pressure ulcers. As they are student nurses working in recognized teaching referral hospital, and are expected to be well practicing, this level of knowledge and practice is below the anticipated. The finding of this study is comparable with other studies conducted in different parts of the world. A study conducted in Addis Ababa Government Hospitals, Ethiopia ${ }^{1} 54.4 \%$ of the participants was found to be knowledgeable. While substantial proportions 45.6 $\%$ were having inadequate. Similarly, the study conducted in Bangladesh indicated that the overall nurses' knowledge on pressure ulcer prevention were found to be $57.79 \%$ [5-8] and the other study conducted in one of the largest health insurance hospital in Alexandria, found that, the overall mean percentage score for nurses were below the minimum acceptable level [9]. This study showed a appositive correlation for knowledge and practices.

\section{Limitations of the Study}

The major limitations of this study include the following:

I. The fact that no study was conducted so far in Andhra Pradesh or India on this topic; no enough literature was available to discuss in national context. 


\section{Nursing \& Healthcare International Journal}

II. The practice component may not be well addressed, as observational checklist was not used.

III. The study may be subjected to response set bias from the respondents.

IV. The study was descriptive therefore; it was difficult to know which occurred first the exposure or the outcome.

\section{Conclusion}

Nurses' knowledge and practice regarding prevention of pressure ulcer was found to be inadequate. There is a significant correlation between knowledge and practices. Pressure ulcer prevention practice was affected by the participant's level of knowledge and practicing skill. The nurse supervisor, faculty and management should conduct In-service training, upgrading courses, continuous monitoring and support and ensuring availability of the necessary facilities and equipments are some of the important steps to improve nurses' knowledge and practice regarding to prevention of pressure ulcer. Effective education on the aspects of SSKIN can bring a positive change in student nurses behavior especially in application of knowledge in practicing prevention of PU in the hospitalized patients.

\section{Recommendations}

1. A similar study can be done among the staff nurses in the hospital setting.

2. A similar study could be carried out by using direct participatory observational check list among the hospital staff nurses.

3. Further interventional studies should be carried out to assess the KAP after nurses participate in the ISE programme.

4. The faculty should take appropriate measures to educate the student nurses by incorporating the aspects of SSKIN to prevent PU in the class room / clinical teaching.

5. Student Nurses need to enhance their knowledge and practices on pressure ulcer prevention in order to further improve nursing practice in this area.

6. Nurses, who had better knowledge and skill, should also teach their respective colleagues who had deficits for the betterment of nursing care.

7. Health service supervisors should identify the perceived barriers of care and then minimize these barriers as much as possible to prevent pressure ulcer.

\section{Ethical Considerations}

Ethical clearance was obtained from Ethical Review Committee of Department of Nursing. Prior written permission from the Principal of the institution was taken. After the purpose and objective of the study had informed, verbal consent was obtained from each study participant. Data were kept anonymously in the distributed questionnaire in order to keep confidentiality.

\section{Conflict of Interest}

Author declares there are no conflicts of interest.

\section{References}

1. Nuru N, Zewdu F, Amsalu S, Mehretie Y (2015) Knowledge and practice of nurses towards prevention of pressure ulcer and associated factors in Gondar University Hospital, Northwest Ethiopia. BMC Nursing 14: 34 .

2. Abebe Dilie and Daniel Mengistu (2015) Assessment of Nurses' Knowledge, Attitude and Perceived Barriers to Expressed Pressure Ulcer Prevention Practice in Addis Ababa Government Hospitals, Addis Ababa, Ethiopia. Advances in Nursing 2015: 11.

3. Uba MN, Alih FI, Kever RT, Lola N (2015) Knowledge, attitude and practice of nurses toward pressure ulcer prevention in University of Maiduguri Teaching Hospital, Borno State, North-Eastern, Nigeria. International Journal of nursing and midwifery $7(4)$ : 54-60.

4. Durkin DM, May R (2015) Stop the Pressure.

5. Maravilla JC, Michelle de Guzman B, Lucero MH, Medina MJC, Marmeto JB, et al. (2012) The knowledge of nurses in pressure ulcer prevention and their attitude towards the use of Braden scale, in Proceedings of the Sigma Theta Tau International's $23^{\text {rd }}$, International Nursing Research Congress.

6. Qaddumi J, Khawaldeh A (2014) Pressure ulcer prevention knowledge among Jordanian nurses: a cross-sectional study BMC Nursing 13(1): 6.

7. Beckford Ball J (2013) Strikethrough Resistant Technology Can Meet the Demands of Healthcare, Pressure Ulcer Prevention 4. 


\section{Nursing \& Healthcare International Journal}

8. Islam S (2010) Knowledge, Attitude and Practice regarding Pressure Ulcer Prevention for Hospitalized Patients at Rajshahi Medical College Hospital in Bangladesh In: Prince of Songkla University.
9. Enein NYAE, Zaghloul AA (2011) Nurses' knowledge of prevention and management of pressure ulcer at a Health Insurance Hospital in Alexandria. Int J Nurs Pract 17(3): 262-268.

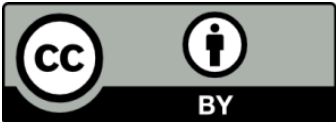

